\title{
Response: Commentary: Managing Recovery Resilience in Coral Reefs Against Climate-Induced Bleaching and Hurricanes: A 15 Year Case Study From Bonaire, Dutch Caribbean
}

\author{
Robert S. Steneck ${ }^{1 *}$, Suzanne N. Arnold ${ }^{2}$, Robert Boenish ${ }^{3}$, Ramón de León ${ }^{4}$, \\ Peter J. Mumby ${ }^{5}$, Douglas B. Rasher ${ }^{6}$ and Margaret W. Wilson ${ }^{7}$ \\ ${ }^{1}$ School of Marine Sciences, University of Maine, Orono, ME, United States, ${ }^{2}$ Marine Science, Island Institute, Rockland, ME, \\ United States, ${ }^{3}$ Environmental Defense Fund, Boston, MA, United States, ${ }^{4}$ Reef Support BV, Bonaire, Netherlands, ${ }^{5}$ Marine \\ Spatial Ecology Lab, University of Queensland, Brisbane, QLD, Australia, ${ }^{6}$ Bigelow Laboratory for Ocean Sciences, \\ East Boothbay, ME, United States, ${ }^{7}$ Bren School of Environmental Science \& Management, University of California, Santa \\ Barbara, Santa Barbara, CA, United States
}

Keywords: coral reef, management, monitoring, Bonaire, sampling methods, Caribbean, recovery resilience, coral reefs

\section{OPEN ACCESS}

Edited by:

Fiorenza Micheli,

Stanford University, United States

Reviewed by:

Nancy Knowiton,

Smithsonian Institution, United States

*Correspondence:

Robert S. Steneck

steneck@maine.edu

Specialty section

This article was submitted to

Marine Conservation and

Sustainability,

a section of the journal

Frontiers in Marine Science

Received: 01 July 2020 Accepted: 28 September 2020 Published: 06 November 2020

Citation:

Steneck RS, Arnold SN, Boenish R, de León R, Mumby PJ, Rasher DB and Wilson MW (2020) Response: Commentary: Managing Recovery Resilience in Coral Reefs Against Climate-Induced Bleaching and Hurricanes: A 15 Year Case Study From Bonaire, Dutch Caribbean.

Front. Mar. Sci. 7:579060. doi: 10.3389/fmars.2020.579060

\section{A Commentary on}

Commentary: Managing Recovery Resilience in Coral Reefs Against Climate-Induced Bleaching and Hurricanes: A 15 Year Case Study From Bonaire, Dutch Caribbean by Meesters, E. H., Bak, R. P. M., and van Duyl, F. C. (2020). Front. Mar. Sci. 7:346. doi: $10.3389 /$ fmars.2020.00346

Meesters et al. (2020) raised concerns about the methodology used and conclusions drawn in our recent paper (Steneck et al., 2019). Specifically, they identified two overarching problems: (1) that our methods result in an inflated estimate of coral cover, and (2) as a result, one might infer that no extra management is needed. Neither concern is legitimate. We use consistent long-term monitoring methodology intentionally designed to monitor changes specifically on coral reefs, not all coastal marine ecosystems. We find that the reefs of Bonaire represent a highly unusual example of a resilient Caribbean reef ecosystem, and argue in our original article that this resilience is due to sustained and effective local management.

Meesters et al. raise three methodological issues: (1) how reefs were chosen, (2) how percent cover was analyzed on those reefs, and (3) whether the resulting estimates of coral cover were unrealistically high. We address these points below.

For comparing or monitoring coral reefs, it is important to use commensurable or identical methods under similar environmental conditions. Therefore, it is necessary to stratify the habitats being studied so comparisons are not between apples and oranges. Variables that should be controlled for when monitoring reefs were well-articulated in Bak (1975): "The factors governing coral distribution are well-known and include: light, sedimentation, water movement, substrate, bottom morphology and temperature." These are precisely the variables we controlled for in choosing coral reef sites to monitor in Bonaire.

The assertion of bias in our "non-random" site selection is partially correct by design. As we explained, our site selection was stratified by depth, substrate and wave exposure. Our bias was that we were studying coral reef ecosystems, not all $10 \mathrm{~m}$ depth benthic habitats surrounding Bonaire. Given those constraints, the Bonaire Marine Park Authority (STINAPA) selected our specific 
monitoring sites. Beyond the described stratification, none of our transects were established with consideration to coral cover per se. However, we did avoid the larger sand channels or "sediment rivers" (sensu Bak, 1975). We had no preconceived notion of where to place our study sites and again, it is somewhat less important for tracking changes in the coral reef over time. However, Meesters et al.'s initial and repeated questions of why our results differed from those of Sommer et al. (2011) and De Bakker et al. (2019) likely related to the lower averages resulting from their transects that included significant amounts of sand. We note that Sommer et al. (2011) reported that, on average, sand (21.9\%) was more abundant than live coral (19.7\%) among all of their $10 \mathrm{~m}$ sites around Bonaire. In fact, their study included the dive site "Red Slave" which is not a coral reef. It had by far the lowest coral cover $(0.8 \%)$ and was reported to be comprised of $80 \%$ sand. The authors suggest that sand dominated substrates may be "attributable to the strong energy gradient operating in the north-east trade wind setting at the southwest fringes of Bonaire." We avoided such habitats when establishing our 11 coral reef monitoring sites. Also, several low relief and low coral cover sites (De Bakker et al., 2019) were dominated by gorgonians (Sommer et al., 2011; Figure 2) but such "gorgonian plains" should not be characterized as coral reefs in ecological assessments (see Williams et al., 2015).

To compare studies, it is necessary to know precisely how coral cover was measured. Following the protocol of the Atlantic and Gulf Rapid Reef Assessment (AGRRA), we monitored coral reefs rather than all subtidal habitats surrounding Bonaire. Therefore, we quantified coral abundance at sites where reefs had developed but not gorgonian pavements or sediment habitats having a scattering of corals. Specifically, we monitored only hard substrates where corals could live as stipulated in the initial AGRRA protocol so we excluded deep sand patches. This approach is especially important for highly dissected reefs. Notably, Meesters et al.'s analysis concluded that correcting for sand "may not have affected estimates of average coral cover too drastically."

There will always be problems making comparisons among studies that used different methods especially when they involve different depths and different habitats (e.g., Williams et al., 2015). For example, Meesters et al. stated that:

\section{Throughout the manuscript this significant [high coral cover] claim is at no point compared to other recent assessments of the Bonaire reef status, even though these coral cover estimates are significantly higher than data for Bonaire collected by us since the 1970's (Bak and Nieuwland, 1995; Bak et al., 2005; De Bakker et al., 2016, 2017) and other researchers (e.g., Sommer et al., 2011)."}

We had considered those five papers but found they reflected data from only two studies in Bonaire both using very different methods and in different habitats from our study. The first, initiated in 1973 and monitored by Bak, photographed a single quadrat distributed over multiple depths to $40 \mathrm{~m}$ at a single site in Bonaire (Karpata). The second study (Sommer et al., 2011, discussed above) used photo transects on multiple reefs from a variety of habitats and environmental conditions at one time. Neither approach was comparable in methods or habitats to our coral reef ecosystem monitoring that quantified multiple variables from multiple reefs at a single depth over the last 15 years. Given the different habitats, methods, depths and sample sizes, we saw little utility in comparing those studies with ours from 11 sites each having multiple replicated $10 \mathrm{~m}$ transects. Bak's studies are certainly useful-for example, they have recorded encroachment of the carpeting macroalga Lobophora toward shallower depths in nearby Curaçao (Nugues and Bak, 2006)-but they do not provide a spatially representative perspective on trends in the health of the coral reef ecosystem in Bonaire (e.g., Steneck and McClanahan, 2005).

Beyond the inconsistent methods (e.g., quadrats vs. transects) applied to different, non-reef sand or gorgonian-dominated habitats that resulted in lower estimates of coral cover, the assertion that our methods resulted in "uniquely high" coral cover in Bonaire is not supported by the literature. In 1999, (Kramer and Bischof, 2003) applied the AGRRA protocol at six of Bonaire's reef sites (recording a total of 51 transects) at $10 \mathrm{~m}$ water depth and found the average coral cover to be $47 \%$. This was identical to the average value we recorded in 2003 using comparable methods at six reef sites at that depth. Further, habitat-stratified benthic transect sampling used in Steneck et al. (2019) was not the reason for the high coral cover reported for Bonaire. The identical method was used by the same investigator at multiple coral reefs along the $740 \mathrm{~km}$ island archipelago in the eastern Caribbean and the average live coral cover at $10 \mathrm{~m}$ was $17.5 \%$ (Steneck et al., 2018). That value of live coral cover is slightly less than the Caribbean-wide average reported in Jackson et al. (2014) and highlighted by Meesters et al. in their commentary.

Finally, it is important to restate that the objectives of the Steneck et al. (2019) study were to shine a spotlight on the importance of good management and its positive impact on coral reef ecosystem resilience. Specifically, we quantified numerous variables that comprise the coral reef ecosystem on Bonaire's leeward shores at $10 \mathrm{~m}$ depth. This is the most commonly studied depth for coral reef monitoring (Lang, 2003; Jackson et al., 2014). We made no claims that our study reflected the ecosystem at shallower or deeper depths. While measuring coral abundance is necessary and important for tracking the status of coral reef ecosystems, so too are censusing macroalgae, sea urchins and herbivorous fishes (especially parrotfishes). We show that a higher than average parrotfish abundance in Bonaire resulted from specific management actions. Spearfishing was banned in 1971. Subsequently, laws were changed in Bonairedirectly as a result of our monitoring reports-that banned the harvest of parrotfish and phased out fish traps. The resultant high abundance of herbivores and paucity of algae helps to explain why coral cover and juvenile coral abundances have remained relatively high in Bonaire as compared to other Caribbean reefs. Perhaps more importantly, following a bleaching event that triggered macroalgal increases, it was the high abundance of herbivores that caused the algae to decline and the reef to recover. 
Very few Caribbean reefs have recovered from large scale coral mortality. That point, rather than the reported percent cover of coral, is what makes Bonaire's coral reefs truly unique. Rather than our study being a disincentive to continue management, we see it as a clear example of how sustaining key management actions can enhance the "recovery resilience" of coral reefs, not only in Bonaire but throughout the Caribbean. Given that large scale reef disturbances are becoming more frequent (Hughes et al., 2017), lessons learned from successful local management resulting in resilient coral reefs are more valuable than ever.

\section{REFERENCES}

Bak, R. P. (1975). Ecological aspects of the distribution of reef corals in the Netherlands Antilles. Bijdragen Dierkunde 45, 181-190.

Bak, R. P. M., and Nieuwland, G. (1995). Long-term change in coral communities along depth gradients over leeward reefs in the Netherlands Antilles. Bull. Mar. Sci. 56, 609-619.

Bak, R. P. M., Nieuwland, G., and Meesters, E. H. (2005). Coral reef crisis in deep and shallow reefs: 30 years of constancy and change in reefs of Curacao and Bonaire. Coral Reefs 24, 475-479. doi: 10.1007/s00338-005-0009-1

De Bakker, D. M., Meesters, E. H., Bak, R. P. M., Nieuwland, G., and Van Duyl, F. C. (2016). Long-term shifts in coral communities on shallow to deep reef slopes of Curaçao and Bonaire: are there any winners? Front. Mar. Sci. 3:247. doi: 10.3389/ fmars.2016.00247

De Bakker, D. M., Van Duyl, F. C., Bak, R. P. M., Nugues, M. M., Nieuwland, G., and Meesters, E. H. (2017). 40 years of benthic community change on the Caribbean reefs of Curaçao and Bonaire: the rise of slimy cyanobacterial mats. Coral Reefs 36, 355-367. doi: 10.1007/s00338-016-1534-9

De Bakker, D. M., Van Duyl, F. C., Perry, C. T., and Meesters, E. H. (2019). Extreme spatial heterogeneity in carbonate accretion potential on a Caribbean fringing reef linked to local human disturbance gradients. Glob. Change Biol. 25, 4092-4104. doi: 10.1111/gcb. 14800

Hughes, T. P., Kerry, J. T., Álvarez-Noriega, M., Álvarez-Romero, J. G., Anderson, K. D., Baird, A. H., et al. (2017). Global warming and recurrent mass bleaching of corals. Nature 543, 373-377. doi: 10.1038/nature21707

Jackson, J., Donovan, M., Cramer, K., and Lam, V. (2014). Status and Trends of Caribbean Coral Reefs: 1970-2012. Gland: Global Coral Reef Monitoring Network, IUCN.

Kramer, P. A., and Bischof, B. G. (2003). “Assessment tables for Abaco, Bahamas (fish), Lighthouse Atoll, Belize (corals, algae, fishes) and Bonaire, Netherlands Antilles (corals, algae, fishes)," in Status of Coral Reefs in the Western Atlantic: Results of Initial Surveys, Atlantic and Gulf Rapid Reef Assessment (AGRRA) Program, ed J. C. Lang (Washington, DC: Atoll Research Bull 496), 591-597.

Lang, J. C. (2003). Status of Coral Reefs in the Western Atlantic. Results of Initial Surveys, Atlantic and Gulf Rapid Reef Assessment (AGRRA) Program. Washington, DC: Atoll Research Bulletin 496.

\section{AUTHOR CONTRIBUTIONS}

All authors edited and contributed to the draft composed by RS.

\section{ACKNOWLEDGMENTS}

We thank the reviewers for their helpful comments to improve our response. Our research in Bonaire was initially funded by the Pew Fellows for Marine Conservation and later supported by STINAPA Bonaire.

Meesters, E. H., Bak, R. P. M., and van Duyl, F. C. (2020). Commentary: managing recovery resilience in coral reefs against climate-induced bleaching and hurricanes: a 15 year case study from Bonaire, Dutch Caribbean. Front. Mar. Sci. 7:346. doi: 10.3389/fmars.2020.00346

Nugues, M. M., and Bak, R. P. M. (2006). Differential competitive abilities between Caribbean coral species and a brown alga: a year of experiments and a longterm perspective. Mar. Ecol. Prog. Ser. 315, 75-86. doi: 10.3354/meps315075

Sommer, B., Harrison, P. L., Brooks, L., and Scheffers, S. R. (2011). Coral community decline at Bonaire, southern Caribbean. Bull. Mar. Sci. 87, 541-565. doi: 10.5343/bms.2010.1046

Steneck, R. S., Arnold, S. N., Boenish, R., De León, R., Mumby, P. J., Rasher, D. B., et al. (2019). Managing recovery resilience in coral reefs against climate induced bleaching and Hurricanes: a 15 year case study from Bonaire, Dutch Caribbean. Front. Mar. Sci. 6:265. doi: 10.3389/fmars.2019.00265

Steneck, R. S., and McClanahan, T. (2005). A Report on the Status of the Coral Reefs of Bonaire in 2005 with Advice on a Monitoring Program. A report to the Bonaire Marine National Park (STINAPA). University of Maine, 106.

Steneck, R. S., Mumby, P. J., MacDonald, C., Rasher, D. B., and Stoyle, G. (2018). Attenuating effects of ecosystem management on coral reefs. Sci. Adv. 4:eaao5493. doi: 10.1126/sciadv.aao5493

Williams, S. M., Mumby, P. J., Chollett, I., and Cortés, J. (2015). Importance of differentiating Orbicella reefs from gorgonian plains for ecological assessments of Caribbean reefs. Mar. Ecol. Prog. Ser. 530, 93-101. doi: 10.3354/meps 11333

Conflict of Interest: The authors declare that the research was conducted in the absence of any commercial or financial relationships that could be construed as a potential conflict of interest.

Copyright (c) 2020 Steneck, Arnold, Boenish, de León, Mumby, Rasher and Wilson. This is an open-access article distributed under the terms of the Creative Commons Attribution License (CC BY). The use, distribution or reproduction in other forums is permitted, provided the original author(s) and the copyright owner(s) are credited and that the original publication in this journal is cited, in accordance with accepted academic practice. No use, distribution or reproduction is permitted which does not comply with these terms. 